6. PRADA ARIAS, M.; VÁZQUEZ CASTELO, J.L.; MONTERO SÁNCHEZ, M. y cols.: "Bazo ectópico supernumerario intraescrotal: Fusión esplenogonadal discontinua". An. Pediatr., 64: 277, 2006.

*7. JANUS, C.L.; MENDELSON, D.S.: "Comparison of MRI and CT for study of renal and perirrenal masses". Crit. Rev. Diag. Imag., 32: 69, 1991.

*8. LASK, D.; ABARBANEL, J.; RECHNIC, Y. y cols.: "Ectopic splenic tissue simulating a renal mass". J. Urol., 153: 1610, 1995.

9. RAO, K.G.; FITZER, P.M.: "Left suprarenal mass following splenectomy: Case reports". J. Urol., 132: 323, 1984.

Casos Clínicos

Arch. Esp. Urol., 61, 1 (78-80), 2008

\section{URETROLITOTRICIA Y CISTOLITOTRICIA DE LITOS URETRALES GIGANTES CON ABORDAJE TRANSPERINEAL}

\section{Jeff R. Cortés González, Jorge A. Arratia Maqueo y} Rodolfo Jaime Dávila.

Servicio de Urología Hospital Universitario Dr. José Eleuterio González. U.A.N.L. Monterrey. Nuevo León. México.

Resumen.- OBJETIVO: Evidenciar que un procedimiento transperineal en una etapa puede ser efectivo en el tratamiento de litiasis uretral secundario a estenosis uretral. MÉTODOS: Se presenta el caso de un paciente masculino de 36 años parapléjico, vejiga neurogénica, historia de cateterismo intermitente y antecedente de estenosis uretral tratado con uretrotomías internas en múltiples ocasiones. Estudios de imagen demuestran litiasis uretral y estenosis uretral concomitante. Se decide realizar abordaje transperineal en una sola etapa.

RESULTADOS: La evolución postoperatoria fue satisfactoria y el paciente fue egresado el día posterior a la intervención. Doce meses después de la cirugía el paciente se encuentra en buenas condiciones generales, sin datos de estenosis y se realiza cateterismos intermitentes sin dificultad.

CONCLUSIÓN: Se realizó un procedimiento en una sola etapa a partir de los tratamientos endoscópicos previos que no fueron exitosos. No existe en nuestro conocimiento ningún caso publicado con litos uretrales del tamaño presentado en este trabajo ni su eventual tratamiento con litotricia y litolapaxia con abordaje transperineal y uretroplastía en un solo tiempo quirúrgico

Palabras clave: Litiasis uretral. Estenosis uretral. Uretroplastía.

Summary.- OBJECTIVE: To show that a one-stage transperi-neal procedure may be effective in the treatment of urethral stones secondary to urethral strictures.

METHODS: We present the case of a $36 \mathrm{y} / \mathrm{o}$ paraplegic male with neurogenic bladder, history of intermittent catheterization, and urethral strictures treated with internal urethrotomies several times. Imaging tests showed the presence of giant urethral and bladder stones with a concomitant bulbar urethra stricture. A one-stage transperineal approach was indicated.

RESULTS: Postoperative follow up was satisfactory. The patient was discharged from the hospital one day after the surgery. At 12 months there were no signs of urethral obstruction and he continued with intermittent catheterizations uneventfully.

CONCLUSION: One stage procedure was indicated because previous endourological treatments were unsuccessful. To our knowledge there is no published case of urethral stones the size we report to or its treatment with lithotripsy and litholapaxy in a one-stage transperineal approach.

Keywords: Urethral stones. Urethral stricture. Urethroplasty.

\section{INTRODUCCIÓN}

Los cálculos uretrales no son comunes. Se asocian a anormalidades anatómicas o cambios postquirúrgicos como estenosis uretrales, divertículos, cuerpos extraños e infección crónica. El tratamiento esta en base a su tamaño, localización y número de litos. Presentamos el caso de un paciente con vejiga neurogénica, estenosis uretral y cálculos uretrales. 

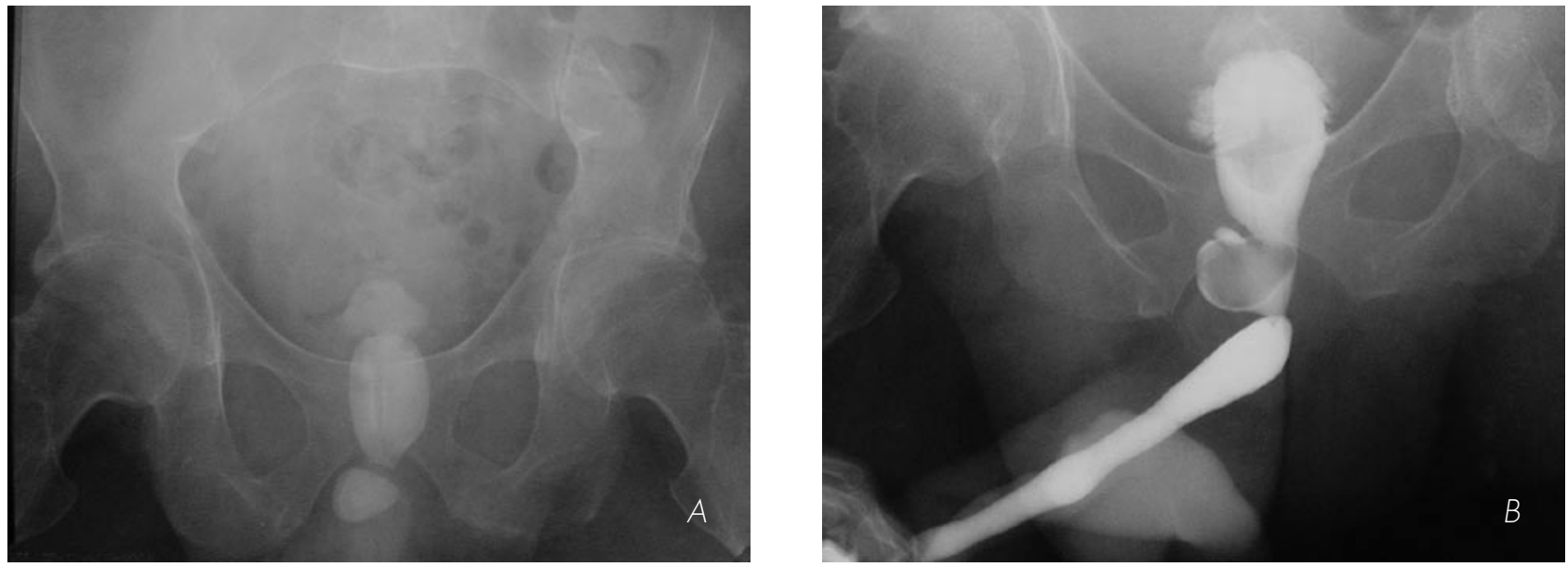

FIGURA 1. Se aprecian imágenes cálcicas en topografía vesical y uretral (A).

Uretrograma que demuestra estenosis uretra bulbar, defecto de llenado en uretra bulbomembranosa e importante dilatación y defecto de llenado en uretra prostática (B).

\section{PRESENTACIÓN DEL CASO Y MANEJO}

Varón de 36 años con antecedente de accidente automovilístico que le ocasiono fracturas de T3, T4 que dejó como secuela paraplejia y vejiga neurogénica. Historia de cateterismo intermitente y antecedente de estenosis uretral tratado con uretrotomías internas en múltiples ocasiones. Acude a nuestra institución tras presentar fiebre, ataque al estado general, nausea y vómito. A la exploración física presenta paraplejia, aumento de volumen en región suprapúbica a expensas de retención urinaria aguda. El ultrasonido y en la placa simple de vías urinarias demostraron la presencia de litos vesicales y uretrales de 3, 1.5, 1.2 y $0.7 \mathrm{~cm}$. (Figura $1 \mathrm{~A}$ ). Se intentó colocar sonda transuretral sin éxito. Se realiza uretrograma retrógrado en el que se aprecia estenosis casi total en uretra bulbomembranosa, litos vesicales, lito en uretra prostática y bulbar. (Figura 1 B). No existe paso de medio de contraste hacia vejiga por lo que se colocó cistostomía percutánea y se inició antibióticotera- pia intravenosa. La terapia con antibióticos fue exitosa. Una vez controlado el cuadro infeccioso y en base a la localización de los litos y la estenosis uretral asociada se decidió realizar abordaje transperineal para uretrolitotomía, cistolitotomía y plastía uretral.

\section{Breve descripción de técnica}

El abordaje se realizó con incisión en $\mathrm{Y}$ invertida perineal con disección roma de la musculatura del piso pélvico hasta llegar a bulbo uretral. (Figura 2 A) Se localizó el área estenótica mediante el paso de dilatador de Vanburen por la cistostomía; se realizó resección de las áreas estenótica y espongiofibrótica; se realizó litotricia y litolapaxia uretral y vesical (Figura 2 B) utilizando Lithoclast; para posteriormente hacer plastía uretral termino terminal.

La evolución postoperatoria fue satisfactoria y el paciente fue egresado el día posterior a la intervención. Doce meses después de la cirugía el paciente se encuentra en
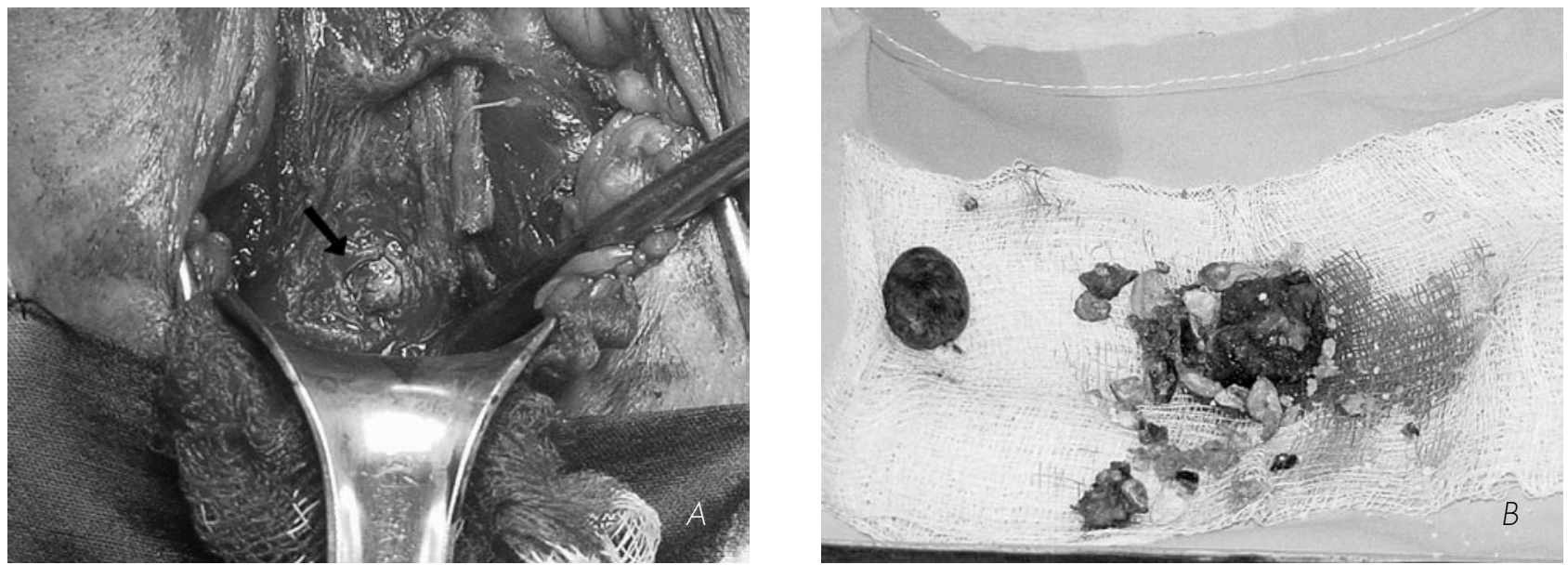

FIGURA 2. Abordaje transperineal donde se aprecia lito flecha (A), Litos uretrales y vesicales posterior a litotricia (B). 
buenas condiciones generales, sin datos de estenosis y se realiza cateterismos intermitentes sin dificultad.
Casos Clínicos

Arch. Esp. Urol., 61, 1 (80-82), 2008

\section{DISCUSIÓN}

La presentación clínica de los litos uretrales así como su tamaño es variable. Regularmente se acompañan de anormalidades anatómicas secundarias a cambios postquirúrgicos, cuerpos extraños, infección, divertículos, etc. $(1,3,4)$. La mayoría de los pacientes acuden con retención urinaria aguda acompañado de dolor perineal, o en el pene. Se requiere el drenaje urgente de la vía urinaria para aliviar los síntomas y eventualmente planear el tratamiento apropiado. El tratamiento apropiado de la litiasis uretral dependerá del sitio de su localización y de las patologías asociadas (1-4), como lo fue en este caso la vejiga de muy poca capacidad la presencia de litos uretrales de gran tamaño y la estenosis uretral asociada. Cada paciente debe de ser individualizado. Múltiples abordajes se han descritos para tratar la litiasis uretral como la uretrolitotomía a cierlo abierto (4), otros han descrito empujar los litos hacia vejiga para eventualmente realizar litotricia (2), ablación de cálculos uretrales con láser de Holmium (3), así como la litotricia endoscópica en caso de no haber estenosis uretral (2).

Se realizó un procedimiento en una sola etapa a partir de los tratamientos endoscópicos previos que no fueron exitosos. Un procedimiento en 2 etapas podría haber adherido morbilidad a este paciente.

Ha habido reportes de formación de litos uretrales tras uretroplastia (1) más no existe, en nuestro conocimiento, ningún caso publicado con litos uretrales del tamaño presentado en este caso ni su eventual tratamiento con litotricia y litolapaxia con abordaje transperineal y plastía uretral en un solo tiempo quirúrgico.

\section{BIBLIOGRAFIA Y LECTURAS RECOMENDADAS ( ${ }^{*}$ lectura de interés $y^{* *}$ lectura fundamental)}

*1. GODWIN, R.J.; CHIR, B.: "Urethral stone formation following urethroplasty". British Journal of Radiology, 39, 113, 1977.

2. EL-SHERIF, A.E.; PRASAD, K.: "Treatment of urethral stones by retrograde manipulation and extracorporeal shock lithotripsy". BJU, 75: 761, 1995.

3. WALKER, B.R.; HAMILTON, B.D.: "Urethral calculi managed with transurethral holmium laser ablation". Journal of pediatric surgery, 36: 16, 2001.

**4. POLO, M.; CABRAS, M.; LICHERI, S. y cols.: "Su un caso di litiasi e stenosi dell'uretra". Minerva urológica e nefrologica, 1990.

\section{METÁSTASIS CUTÁNEA DURANTE EL SEGUIMIENTO DE CARCINOMA RENAL DE CELULAS CLARAS}

\author{
R. Martínez-Rodríguez, F. Rodríguez-Escovar, A. Bujons \\ Tur, P. Maroto', J. Palou y H. Villavicencio.
}

Servicio Oncologia' Hospital Santa Creu y St Pau. Barcelona.

Servicio de Urología Fundació Puigvert. Barcelona. España.

Resumen.- OBJETIVO: Añadir un nuevo caso de carcinoma renal metastático de localización atípica a la literatura. La afectación cutánea metastásica de los tumores urológicos constituye una entidad clínica rara. Suelen asociarse con afectación interna por lo que su hallazgo ensombrece el pronóstico. Se revisan las localizaciones metastásicas más frecuentes, su implicación pronostica y tratamiento.

MÉTODOS: Se presenta el caso de un paciente varón de 60 años diagnosticado de metástasis cutánea en maxilar inferior a los 18 meses de la nefrectomía radical por adenocarcinoma de células claras.

RESULTADOS: El paciente fue tratado mediante la administración oral de Sorafenib en el marco de un ensayo clínico fase II. El paciente esta vivo y libre de progresión a los 2 años del diagnóstico.

CONCLUSIONES: La amplia variabilidad de localizaciones y formas de presentación del carcinoma renal metastático obligan a mantenerse alerta durante el seguimiento. Los nuevos fármacos de acción antiangiogénica constituyen una opción eficaz de tratamiento.

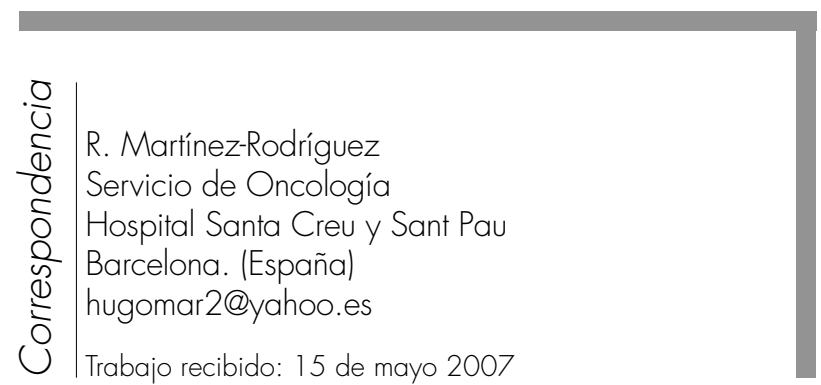

